\title{
Investigation on Gas-Soot Flow Distribution Characteristic of Soot Capture Process in the Wall-Flow Diesel Particulate Filter
}

\author{
Jianyu Li $\mathbb{D},{ }^{1}$ Chunping Lu $\mathbb{D},{ }^{1,2}$ and Dongli Tan $\mathbb{D}^{3}$ \\ ${ }^{1}$ Hunan Valin Xiangtan Iron \& Steel Co., Ltd, Xiangtan 411101, China \\ ${ }^{2}$ China Metallurgic Jingcheng (Xiangtan) Heavy Industry Equipment Co., Ltd, Xiangtan 411200, China \\ ${ }^{3}$ Institute of the New Energy and Energy-Saving \& Emission-Reduction, Guangxi University of Science and Technology, \\ Liuzhou 545006, China \\ Correspondence should be addressed to Dongli Tan; tandongli2008@163.com
}

Received 15 November 2020; Revised 21 December 2020; Accepted 4 January 2021; Published 27 January 2021

Academic Editor: Gang Wu

Copyright (C) 2021 Jianyu Li et al. This is an open access article distributed under the Creative Commons Attribution License, which permits unrestricted use, distribution, and reproduction in any medium, provided the original work is properly cited.

\begin{abstract}
In order to investigate the distribution characteristics of gas-particle two-phase flow in the diesel particulate filter in the capture process, a mathematical model of gas-particle two-phase flow for inside-and-outside filter had been established in the capture process according to the mass conservation equation, momentum conservation equation, and $k-\varepsilon$ turbulence equation. The model verification was carried out with the experimental and simulated of flow distribution characteristics of gas-particle twophase. The obtained results showed that the static pressure gradient along the radial distribution was greater at the inlet of the filter in capture process in the diesel particulate filter, which could easily lead to causing eventual fatigue damage due to stress concentration in the front-end of filter; moreover, the weaker the vortex strength of gas-particle formed in expansion pipe was, the better uniformity of flow velocity and soot concentration distribution were. Therefore, the established mathematical model can be used for predicting gas-particle flow velocity distribution in the diesel particulate filter.
\end{abstract}

\section{Introduction}

It is well known that a critical factor in the city's pollution is the exhaust pollution [1-3]. The emission, especially the particle matter from the diesel engine, is the main source of air pollution $[4,5]$, which seriously affects people's physical and mental health and quality of life, but also hinders the sustainable development of the city [6-8]. Thus, controlling the exhaust pollution of the diesel engine to protect the atmospheric environment has become an important issue and strategic task for the international automobile industry to spend a lot of human [9], financial [10, 11], and material resources [12]. The improvement of the emission control technology for the diesel engine can improve the environmental quality [12-15], complete the integrity and stability of the ecosystem $[13,14]$, and promote the high integration with environmental protection [15] and economic society [16]. So human health has been fully guaranteed and eventually improved the national sustainable development capacity [17].
The diesel particulate filter is considered to be the most promising solution to reduce the level of PM emissions to the ambient background levels $[18,19]$. At present, the research on diesel particulate filter mostly focuses on capturing efficiency of the diesel particulate filter, deposition characteristics of gas-particle motion inside filter, and filter regeneration $[20,21]$, while the research work on the distribution characteristics of the particle flow in the diesel particulate filter had been limited [22]. In fact, utilization ratio, regeneration cycle length, and service life of the filter in the diesel particulate filter are determined by the distribution characteristics of the particle flow [23], especially the uniformity distribution characteristics of the flow velocity and the soot concentration in the diesel particulate filter [24].

At present, the problems of the gas-particle two-phase flow mainly are solved through the analysis of gas-particle two-phase interaction, with the analytic methods of which including tracking the movement orbits of particle by using Lagrange coordinate and researching mixed-phase movement in Euler coordinate system [25]; in former, it is more 
difficult to obtain the spatial distribution of continuous particle velocity and concentration and a great deal of calculation is needed in pseudo particle model because that particle-phase and gas-phase are separated [26]. On the other hand, in latter, it is easy to describe the concentration field of particle-phase and just only small amount of calculation is need [27]. Due to the greater differences between flow principle and flow characteristics when air flow through inside and outside filter, thus it is necessary to separately establish mathematical models for gas-particle flow inside and outside of filter $[28,29]$.

Therefore, based on the gas-particle flow theory and porous medium theory, the gas-particle flow characteristics in the diesel particulate filter are studied in the paper. The calculation and analysis show that distribution characteristics of the flow velocity and the soot concentration are obtained, which will provide important theoretical basis for optimizing and designing new-type diesel particulate filter device and controlling of the regeneration process.

\section{Model and Method of Soot Capture Process in the Diesel Particulate Filter}

2.1. Working Principle of Diesel Particulate Filter. As shown in Figure 1, the diesel particulate filter is comprised of an air inlet pipe, expansion pipe, filter, shrink pipe, and exhaust pipe. Black smoke containing carbon particles from diesel engine enters into the diesel particulate filter through a special pipeline and flows through its internal intensive-setting filter; meanwhile, carbon particles are absorbed on the wallflow honeycomb ceramic filter.

With the increase of working time, the particles in the diesel particulate filter are increased gradually and lead to the increase of the engine back pressure and the decrease of the performance of the diesel engine. Finally, deposition particles are removed by means of recycling technology and then filtration performance is recovered for the diesel particulate filter.

2.2. Establishment of Mathematical Models. As shown in Figure 2, according to the flow characteristics of the capture process in the diesel particulate filter, some assumptions may be made as the follows:

(a) When exhaust flowing through the filter wall, it will not be flowed from the filter wall in directions $y$ and $z$; hence, seepage velocity and soot concentration gradient in directions $y$ and $z$ are much less than that in direction $x$; therefore, the soot concentration is assumed to be constant in directions $y$ and $z$ when exhaust flowing through the filter wall

(b) According to the research [30], change of seepage velocity at the filter wall is very small in direction $x$; therefore, it can be regarded as a constant

(c) For clean filter, the porosity, permeability, and micropore size of filtration surface are all assumed to be equal everywhere [31] (d) For convenience of calculating the flow resistance of the filter, the hypotheses proposed from $[30,32]$ are used in this paper, i.e., particle layer formed on the surface of a filter wall is assumed to be uniform distribute along directions $y$ and $z$

2.2.1. Mathematical Model of Gas-Particle Two-Phase Flow Outside Filter. Research results show that a vortex is produced by exhaust gas when flowing through the expansion pipe [33], so there is turbulent motion for exhaust outside filter in the diesel particulate filter. In this model establishment, the $k-\varepsilon$ turbulent model is used to describe the turbulence phenomenon.

The mass conservation equation of gas-particle twophase flow outside filter is expressed as Eq. (1).

$$
\frac{\partial\left(\alpha_{i} \rho_{i} u_{i}\right)}{\partial x}+\frac{\partial\left(\alpha_{i} \rho_{i} v_{i}\right)}{\partial y}+\frac{\partial\left(\alpha_{i} \rho_{i} w_{i}\right)}{\partial z}=(-1)^{i} \sum m
$$

where $i=1$ denotes gas-phase and $i=2$ denotes particlephase; $\rho_{i}$ is the material density of gas-phase (or particlephase); $u_{i}, v_{i}$, and $w_{i}$, respectively, are velocity in directions $x, y$, and $z$ for gas-phase (or particle-phase); $\sum m$ is the quality source propagation of gas-phase (or particle-phase); $\alpha_{i}$ is the volume fraction of gas-phase (or particle-phase) where the relation satisfied $\alpha_{1}+\alpha_{2}=1$.

The momentum conservation equation of gas-particle two-phase flow outside filter is expressed as Eq. (2).

$$
\begin{aligned}
& \frac{\partial\left(\alpha_{i} \rho_{i} u_{i} u_{i}\right)}{\partial x}+\frac{\partial\left(\alpha_{i} \rho_{i} u_{i} v_{i}\right)}{\partial y}+\frac{\partial\left(\alpha_{i} \rho_{i} u_{i} w_{i}\right)}{\partial z} \\
& =\frac{-\alpha_{i} \partial p}{\partial x_{i}}+\nabla \cdot \tau_{i}+\sum R_{\mathrm{in}}+\alpha_{i} \rho_{i}\left(F_{\mathrm{in}}+F_{\mathrm{lift}, \text { in }}+F_{V m, \text { in }}\right)
\end{aligned}
$$

where $x_{i}$, respectively, are the directions $x, y$, and $z$ when $i=1$ , 2 , and $3 ; u_{\text {in }}, R_{\text {in }}, F_{\text {in }}, F_{\text {lift,in }}$, and $F_{V m \text {,in }}$, respectively, are the velocity in directions $x, y$, and $z$ of the gas-phase (or the particle-phase), interaction force, and external body force as well as virtual mass force; $\boldsymbol{\tau}_{i}$ is the pressure-strain tensor of the gas-phase (or the particle-phase).

The $k-\varepsilon$ turbulent equation of the gas-particle two-phase flow outside filter is expressed as Eq. (3).

$$
\begin{gathered}
\frac{\partial\left(\rho_{m} u_{m} k\right)}{\partial x}+\frac{\partial\left(\rho_{m} v_{m} k\right)}{\partial y}+\frac{\partial\left(\rho_{m} w_{m} k\right)}{\partial z} \\
=\frac{\partial}{\partial x}\left(\frac{\mu_{t, m}}{\sigma_{k}} \cdot \frac{\partial k}{\partial x}\right)+\frac{\partial}{\partial y}\left(\frac{\mu_{t, m}}{\sigma_{k}} \cdot \frac{\partial k}{\partial y}\right) \\
+\frac{\partial}{\partial z}\left(\frac{\mu_{t, m}}{\sigma_{k}} \cdot \frac{\partial k}{\partial z}\right)+G_{k, m}-\rho_{m} \varepsilon
\end{gathered}
$$

where $k$ is the turbulent kinetic energy; $\varepsilon$ is the turbulent dissipation rate; $\rho_{m}$ is the mixed density of gas-phase and particle-phase; $\mu_{t, m}$ is the turbulent viscosity; $G_{k, m}$ is the production term of turbulent kinetic energy; $\sigma_{k}$ is the Prandtl number corresponding to turbulent kinetic energy. 


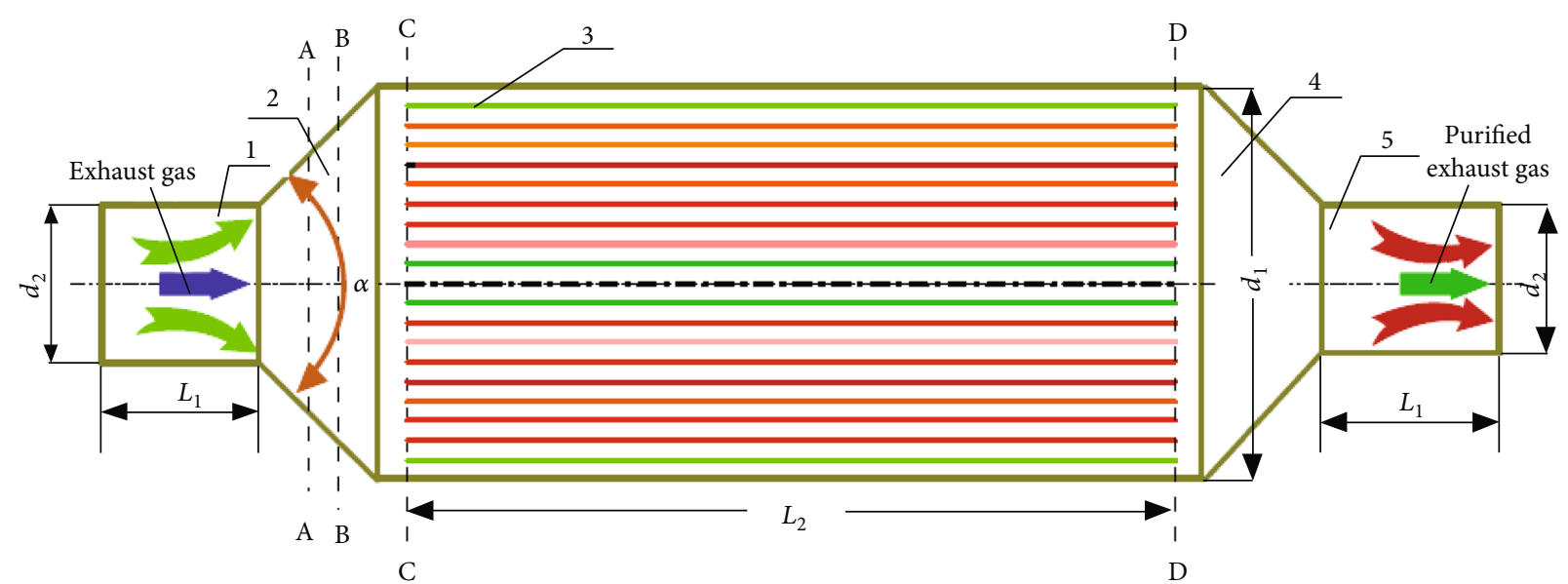

FIGURE 1: Structure of the diesel particulate filter. Note: A, B, C, and D: the relative position of each calculation section; 1: inlet pipe; 2 : expansion pipe; 3: filter; 4: shrink pipe; 5: exhaust pipe.

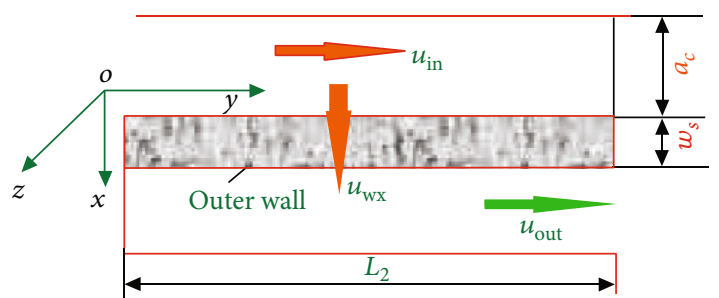

Figure 2: Model of inlet and outlet channel of the DPF.

Based on Eq. (1)-Eq. (3), Eq. (4) can be obtained.

$$
\begin{aligned}
\frac{\partial\left(\rho_{m} u_{m} \varepsilon\right)}{\partial x}+\frac{\partial\left(\rho_{m} v_{m} \varepsilon\right)}{\partial y}+\frac{\partial\left(\rho_{m} w_{m} \varepsilon\right)}{\partial z} \\
=\frac{\partial}{\partial x}\left(\frac{\mu_{t, m}}{\sigma_{\varepsilon}} \cdot \frac{\partial \varepsilon}{\partial x}\right)+\frac{\partial}{\partial y}\left(\frac{\mu_{t, m}}{\sigma_{\varepsilon}} \cdot \frac{\partial \varepsilon}{\partial y}\right)+\frac{\partial}{\partial z}\left(\frac{\mu_{t, m}}{\sigma_{\varepsilon}} \cdot \frac{\partial \varepsilon}{\partial z}\right) \\
\quad+\frac{\varepsilon}{k}\left(C_{1 \varepsilon} G_{k, m}-C_{2 \varepsilon} \rho_{m} \varepsilon\right),
\end{aligned}
$$

where $C_{1 \varepsilon}, C_{2 \varepsilon}$, and $\sigma_{\varepsilon}$ are the model constants; according to recommended values and subsequent experiments, $C_{1 \varepsilon}=$ $1.44, C_{2 \varepsilon}=1.92$, and $\sigma_{\varepsilon}=1.3$.

\subsubsection{Mathematical Model of Gas-Particle Two-Phase Flow} inside Filter. For the reason that the diesel particulate filter is actually a porous medium with seepage characteristics, so the fundamental equations of the gas-particle two-phase flow inside filter are established by using porous medium theory and multifluid model theory.

The mass conservation equation of gas-particle twophase flow inside filter is expressed as Eq. (5).

$$
\frac{\partial\left(\delta \alpha_{i} \rho_{i} u_{i}\right)}{\partial x}+\frac{\partial\left(\delta \alpha_{i} \rho_{i} v_{i}\right)}{\partial y}+\frac{\partial\left(\delta \alpha_{i} \rho_{i} w_{i}\right)}{\partial z}=(-1)^{i} \sum m
$$

where $\delta$ is the porosity of porous medium.
The momentum conservation equation of the gasparticle two-phase flow inside the filter is expressed as Eq. (6).

$$
\begin{gathered}
\frac{\partial\left(\delta \alpha_{i} \rho_{i} u_{i} u_{i}\right)}{\partial x}+\frac{\partial\left(\delta \alpha_{i} \rho_{i} u_{i} v_{i}\right)}{\partial y}+\frac{\partial\left(\delta \alpha_{i} \rho_{i} u_{i} w_{i}\right)}{\partial z} \\
=-\alpha_{i} \frac{\partial(\delta p)}{\partial x}+\nabla \cdot\left(\delta \tau_{i}\right)+\sum R_{\text {in }}+\alpha_{i} \rho_{i} \\
\cdot\left(F_{\text {in }}+F_{\text {lift,in }}+F_{V m, \text { in }}\right)+\alpha_{i} \frac{\mu}{\kappa} u_{\text {in }},
\end{gathered}
$$

where $\alpha_{i} \mu u_{\text {in }} / \kappa$ is the seepage resistance of porous medium for gas-phase (or particle-phase); $\kappa$ is the seepage rate.

2.3. Initial Conditions and Boundary Conditions. It is assumed that the inlet airflow is impressed, and its speed without radial component is uniform. So velocity boundary conditions are used as inlet boundary conditions, and pressure boundary conditions are used as outlet boundary conditions, where the outlet pressure boundary conditions are set to zero and the pressure just only considers the relative value. No slip boundary conditions are imposed on the entire wall, namely, all velocity components are taken as zero.

For the temperature of exhaust gas from the diesel, engine is about $300^{\circ} \mathrm{C}$; therefore, temperature of the material density and dynamic viscosity of the gas-phase are set to $300^{\circ} \mathrm{C}$ too.

Taken turbulence intensity and hydraulic diameter as the turbulence inputs, turbulence intensity $I$ can be calculated as Eq. (7).

$$
I=0.16 \mathrm{Re}^{-1 / 8}
$$

where $\operatorname{Re}$ is the Reynolds number, and $\operatorname{Re}=U d / v$; then, $U$ is the fluid velocity, $\mathrm{m} / \mathrm{s} ; D$ is the diameter of air inlet pipe, $\mathrm{m} ; v$ is the kinematic viscosity, $\mathrm{m}^{2} / \mathrm{s}$.

At present, the exhaust particle diameter of diesel engine is about $0.1 \sim 1 \mu \mathrm{m}$ in range, and the particle diameter is set to $0.5 \mu \mathrm{m}$ in the paper. 
TABle 1: Numerical simulation of the input parameters.

\begin{tabular}{lcc}
\hline SN & Input parameters & Value \\
\hline 1 & Inlet velocity of gas-phase $u_{\text {in }} /\left(\mathrm{m} \cdot \mathrm{s}^{-1}\right)$ & 50 \\
2 & Inlet velocity of particle-phase $u_{\text {sin }} /\left(\mathrm{m} \cdot \mathrm{s}^{-1}\right)$ & 50 \\
3 & Volume fraction of particle-phase $\alpha_{2}$ & 0.05 \\
4 & Material density of gas-phase $\rho_{1} /\left(\mathrm{kg} \cdot \mathrm{m}^{-3}\right)$ & 0.3827 \\
5 & Dynamic viscosity of gas-phase $/(\mathrm{Pa} \cdot \mathrm{s})$ & $2.946 \times 10^{-5}$ \\
6 & Material density of particle-phase $\rho_{2} /\left(\mathrm{kg} \cdot \mathrm{m}^{-3}\right)$ & 1600 \\
7 & Diameter of particle-phase $d_{s} / \mu \mathrm{m}$ & 0.5 \\
8 & Turbulence intensity & 0.43 \\
9 & Hydraulic diameter $d / \mathrm{mm}$ & 50 \\
\hline
\end{tabular}

For that, the main components of the exhaust particulate from diesel engine are carbon (about 75\%) whose density is $2000 \mathrm{~kg} / \mathrm{m}^{3}$, and the $25 \%$ of the exhaust particulate rests are high boiling hydrocarbon. Therefore, the density of the particle material can be estimated to $1600 \mathrm{~kg} / \mathrm{m}^{3}$.

Literature [30] pointed out the apparent density of the exhaust particulate from diesel engine is $75 \mathrm{~kg} / \mathrm{m}^{3}$. Therefore, the volume fraction of inlet particle can be estimated to 0.05 according to Eq. (8).

$$
\alpha=\frac{\rho_{b}}{\rho_{s}}
$$

where $\rho_{b}$ and $\rho_{s}$, respectively, are the particle apparent density and the material density $\left(\mathrm{kg} / \mathrm{m}^{3}\right)$.

Input parameters are expressed as shown in Table 1 in calculating process.

2.4. Meshing of Geometric Model. The geometric model of the diesel particulate filter is meshed by using the GAMBIT software with unstructured grids mixed with hexahedron and wedge. In order to calculate more accurate flow characteristics of expansion pipe, the mesh size of expansion pipe is set to 5 and the others are set to 5 .

Take the Table 2, for example, the meshing numbers of the air inlet pipe and expansion pipe, filter, and outlet pipe are, respectively, 277582, 252442, and 164768 .

In order to improve calculation accuracy, the type of the two-order upwind difference is used for discrete momentum equations [34] and the Interphase Slip Algorithm (IPSA) is used to solve the meshing model of the diesel particulate filter $[35,36]$.

2.5. Model Validation. In the paper, it is due to the fact that exhaust gas of the diesel engine is discharged in the pulse form accompanied by intense pressure fluctuation, accumulation of the soot particles will affect the measurement of flow velocity in the experimental process. The measurement of the flow characteristics cannot be operated in a diesel engine exhaust system. Therefore, considering that the experiment mainly focuses on the study of the distribution characteristics of the flow velocity, the experimental device can satisfy the requirements of the experiment. And airflow velocity is measured by the hot wire anemometer with type AN1002. The
TABLE 2: Structural parameters of diesel particulate filter.

\begin{tabular}{lcc}
\hline SN & Structural parameters & Value \\
\hline 1 & Diameter $d_{1}$ of the diesel particulate filter $/ \mathrm{mm}$ & 160 \\
2 & Length $L_{1}$ of the channel $/ \mathrm{mm}$ & 75 \\
3 & Filter length $L_{2} / \mathrm{mm}$ & 305 \\
4 & Length $L_{3}$ of porous medium $/ \mathrm{mm}$ & 0.5 \\
5 & Wall thickness $w_{s}$ of the channel $/ \mathrm{mm}$ & 0.31 \\
6 & Porosity $\delta$ & 0.5 \\
7 & Diameter $d_{2}$ of inlet channel $/ \mathrm{mm}$ & 50 \\
8 & Cone angle $\alpha$ of expansion pipe $/^{\circ}$ & 60 \\
\hline
\end{tabular}

schematic diagram of experimental equipment is shown in Figure 3.

When the inlet velocity is changed, the relevant parameters will change. But the changed trends are very similar. Thus, in the conditions of the inlet velocity of exhaust remaining a constant $40 \mathrm{~m} / \mathrm{s}$, the measurement values and the simulation values of the axial velocity in section $\mathrm{A}-\mathrm{A}$, section $\mathrm{B}-\mathrm{B}$, and section $\mathrm{C}-\mathrm{C}$ are shown in Figure 4. As shown in Figure 4, the simulation values of airflow velocity match with the actual measurement values. The difference between the actual measurement value and the simulation value is mainly caused by self-measurement error, the precision of the instrument, and the simplification of the mathematical model.

In general, the simulation values of the airflow velocity in the diesel particulate filter agree with the measurement value. In addition, the relative error of maximum difference between the actual measurement value and the simulation value is less than $4.6 \%$. Therefore, the established mathematical model in the paper can be employed to predict gas-particle flow velocity distribution of the diesel particulate filter.

\section{Analysis on Simulation Results}

3.1. Calculation and Analysis of Gas-Phase Flow Characteristics. The distribution characteristics of axial velocity and radial velocity of expansion pipe are shown in Figure 5 in section A-A (where $X=90 \mathrm{~mm}$ ), section B-B (where $X=125 \mathrm{~mm}$ ), section C-C (inlet-end surface of the filter, where $X=150 \mathrm{~mm}$ ), and section $\mathrm{D}-\mathrm{D}$ (the outlet-end surface of the filter, where $X=435 \mathrm{~mm}$ ).

As shown in Figure 5, an axial airflow velocity indicated a gradual decrease in the 4 sections with the radial position increasing. The axial airflow velocity both in section I and section II are negative, indicating that there is a vortex existing on those two sections. From the negative abscissa range, it is obvious that the vortex region area of section I is bigger than that of section II. This is because section II is near the filter, and the vortex region around section II is caused by the interaction from the increase of the diameter of the expansion pipe and the recirculation of the exhaust gas on the filter face. Moreover, Figure 5 can also show that vortex phenomena do not appear in the inlet surface of the diesel particulate filter or the outlet surface of the PDF.

Due to the comparative analysis on the axial velocity change of the exhaust gas on four sections as shown in Figure 5(a), it 


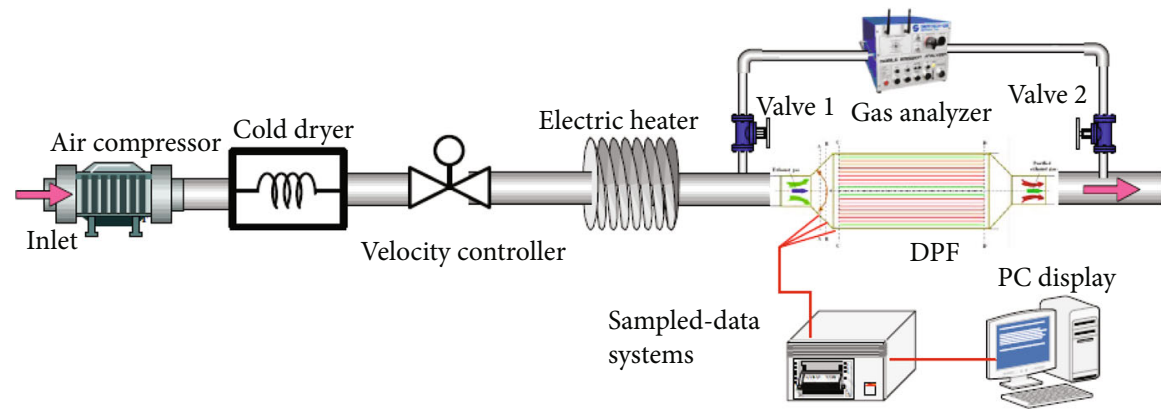

FIgURE 3: Schematic diagram of experimental equipment.

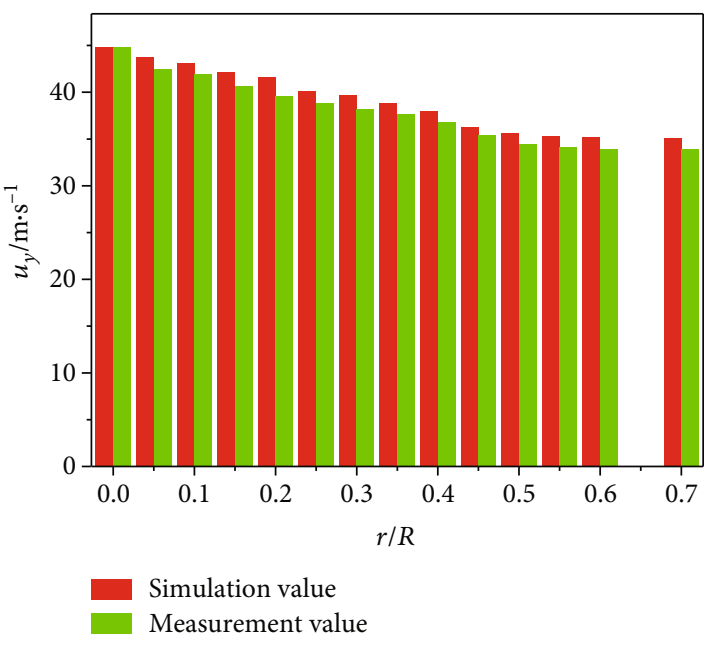

(a)

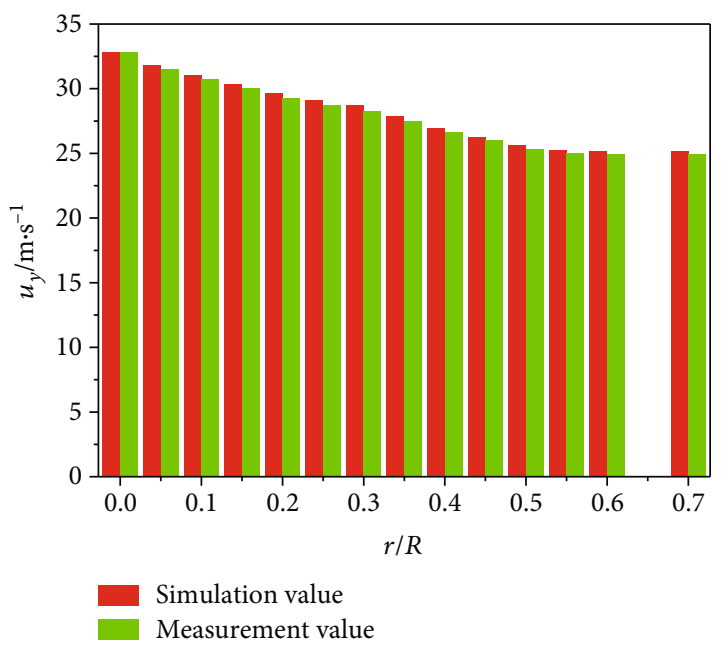

(b)

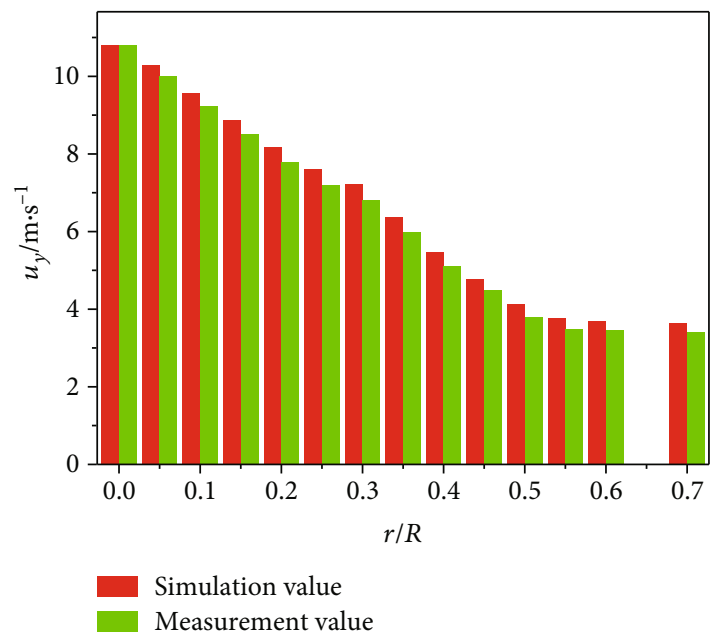

(c)

FIGURE 4: Comparisons of the measurement values and the simulation values.

can be concluded that the larger axial position from the inlet is, the smaller the difference of the axial velocity of the exhaust gas between the center line and the boundary of the diesel particulate filter is, which shows that the axial velocity of the exhaust gas is of better uniformity along the radial direction.

Curve 3 and curve 4 in Figure 5(a) also show that the axial velocity distribution of the exhaust gas from the inlet to the out- let of the diesel particulate filter. And it can be concluded that the axial velocity of the exhaust gas is of better uniformity along the axial direction of the diesel particulate filter; therefore, the differences of the flame propagation velocity in each filter's pore channel are small in the heating regeneration process, which is very useful for improving the regeneration efficiency in the heating regeneration process of the diesel particulate filter. 


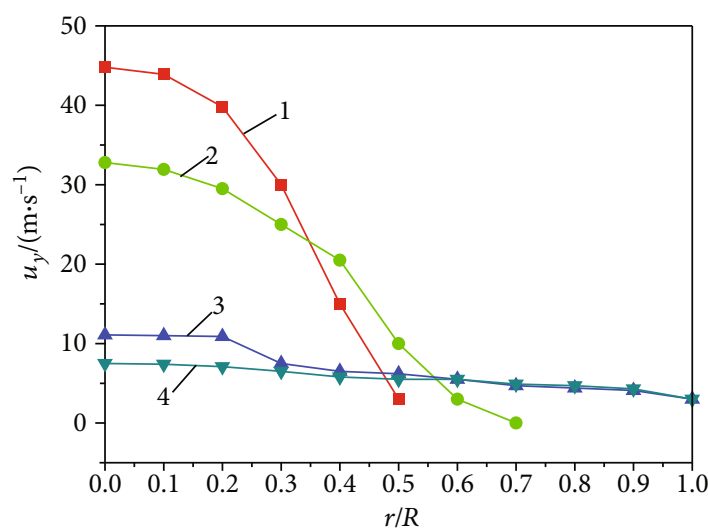

(1) $X=90 \mathrm{~mm}$

(2) $X=125 \mathrm{~mm}$

(3) $X=150 \mathrm{~mm}$

(4) $X=435 \mathrm{~mm}$

(a) Axial velocity of the exhaust gas

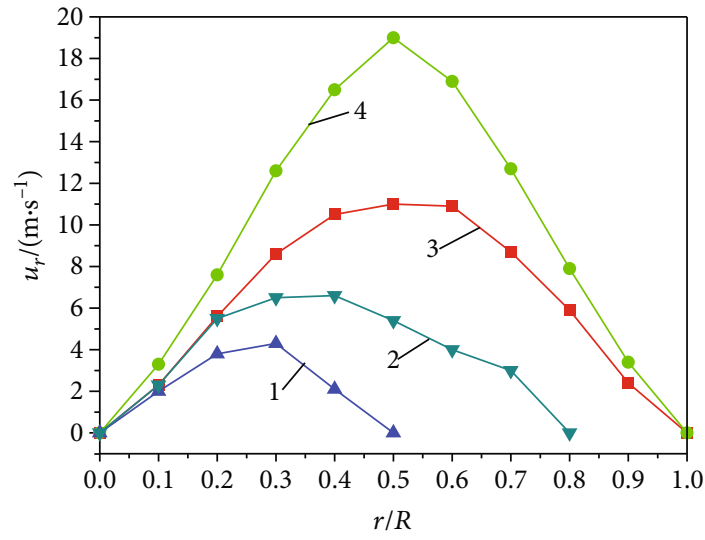
(1) $X=90 \mathrm{~mm}$
(3) $X=150 \mathrm{~mm}$
(2) $X=125 \mathrm{~mm}$
(4) $X=435 \mathrm{~mm}$

(b) Radial velocity of the exhaust gas

FIGURE 5: Velocity distribution of the exhaust gas of the diesel particulate filter.

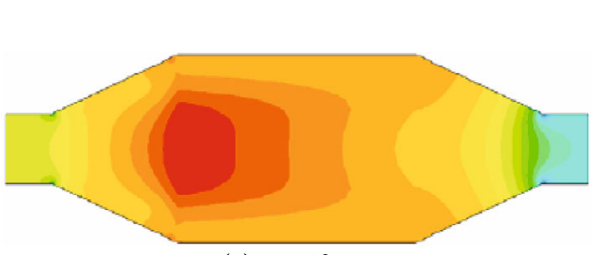

(a) $\alpha=50^{\circ}$

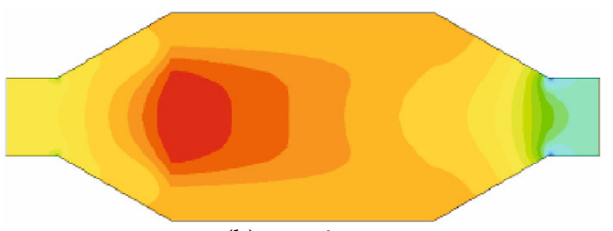

(b) $\alpha=60^{\circ}$

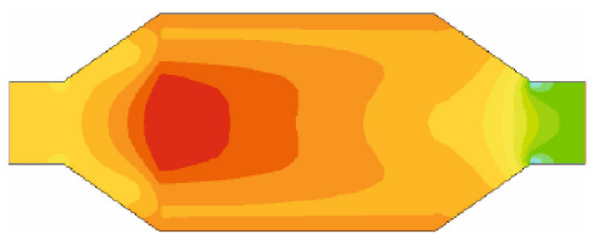

(c) $\alpha=70^{\circ}$

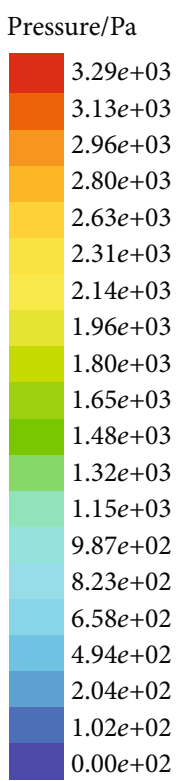

$0.00 e+02$
FIGURE 6: Pressure distribution of the diesel particulate filter.

Figure 5(b) shows the distribution of the gas-phase velocity along the radial direction. As shown in Figure 5(b), the radial gas-phase velocities in sections $\mathrm{A}-\mathrm{A}, \mathrm{B}-\mathrm{B}$, and $\mathrm{C}-\mathrm{C}$ are regularly changed from increase to decrease and their maximum is increased gradually with the increase of the radial position. For example, there is the maximum of the radial gas-phase velocity in section II when $r / R=0.54$.

Figure 6 reveals pressure distribution of the diesel particulate filter. As shown in Figure 6(a), there is the vast majority of pressure loss of the diesel particulate filter on the wall surface of wall-flow honeycomb ceramic filter and there is the other pressure loss resulting from frictional resistance in the channel and local resistance in the inlet and the outlet for section mutation. Pressure loss in the channel of the filter is the main pressure loss in the diesel particulate filter. Fur- thermore, the region nearby expansion pipe and shrink pipe is also an important part producing pressure loss.

As shown in Figure 6, for the diesel particulate filter, there is the maximum value of the static pressure in the center of the inlet-end surface where the gradient of the static pressure is larger along the radial, which will cause stress concentration on the front-end of the diesel particulate filter and even lead to producing fatigue damage in the filter forepart.

3.2. Calculation and Analysis on the Characteristics of the Particle-Phase Flow. Comparison chart of particle velocity with gas velocity for section B-B is shown in Figure 7.

Obviously, the axial velocity of particle-phase in section II is slightly lower than that of the gas-phase, but radial velocity of particle-phase in section II is slightly higher than that of the gas-phase. Those illustrate that there is the relatively small difference between the particle velocity and the gas velocity.

The soot concentration distribution of the diesel particulate filter in the capture process is shown in Figure 8. In sections I and II of expansion region, the soot concentration first remains about 0.05 , then decreases slowly, and finally turns back to increase with the change of the radial position.

Compared with Figure 5, vortex phenomenon causes soot concentration in section $\mathrm{A}-\mathrm{A}$ and section $\mathrm{B}-\mathrm{B}$ being decreased, and the radial position in section $\mathrm{A}-\mathrm{A}$ and section $\mathrm{B}-\mathrm{B}$ where the soot concentration begins to decrease matches with radial position where axial and radial gas-phase velocity become negative. This is because the centrifugal force caused by the vortex makes the particles separated to all directions, which will lead to the decrease of the soot concentration in vortex center. With the increase of radial position, vortex intensity will decrease gradually along radial position, and soot concentration will gradually increase in the position where vortex intensity is relatively weak.

As shown in Figure 8, with the increase of radial position, there is a smaller change of the soot concentration in section I, but there is the larger change of the soot concentration in section III. For example, the soot concentration in section 


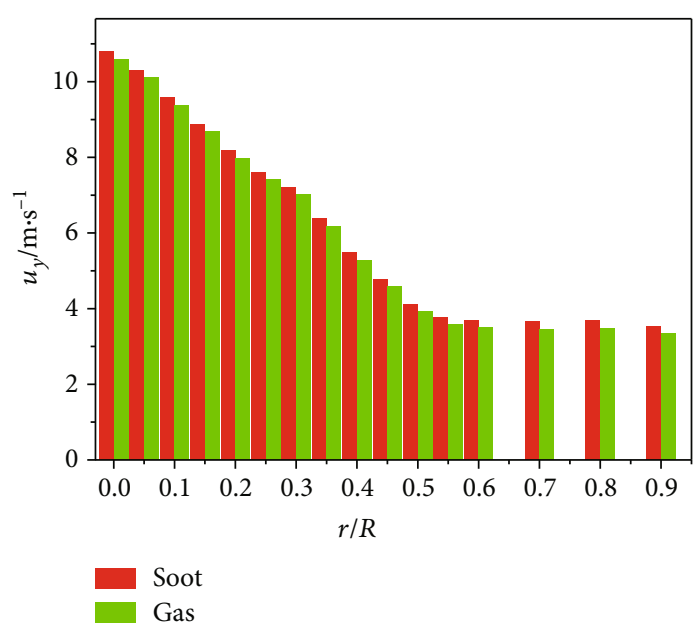

(a) Axial direction

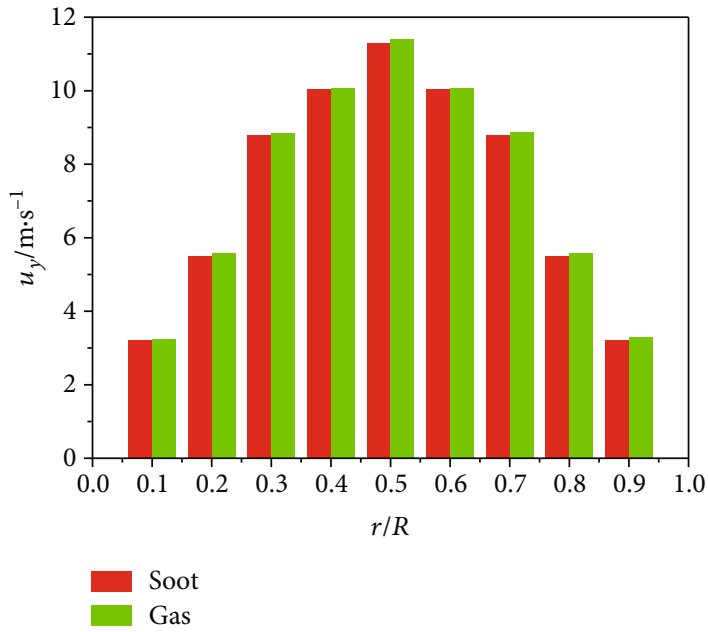

(b) Radial direction

FIGURE 7: Comparison chart in section B-B between the soot velocity and the gas velocity.

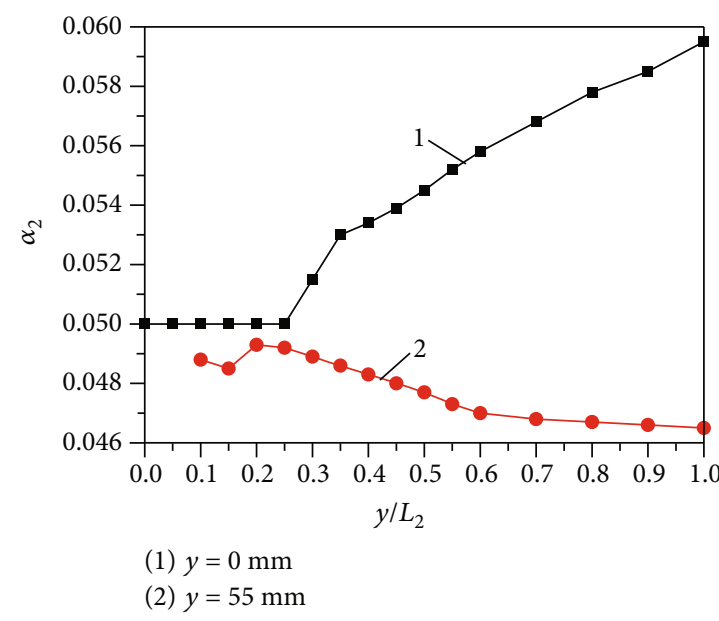

(a) Radial direction

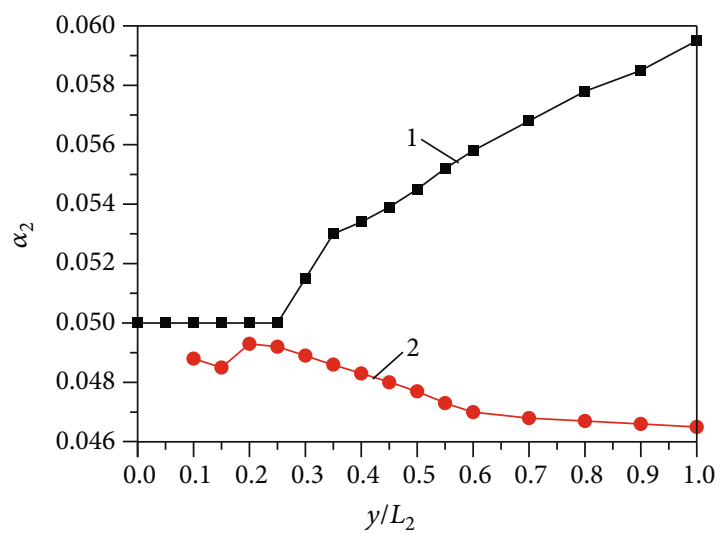

(1) $y=0 \mathrm{~mm}$

(2) $y=55 \mathrm{~mm}$

(b) Axial direction

FIGURE 8: Soot concentration distribution of the DPF in the capture process.

III slowly decreases from the maximum value (namely, 0.0567 ) to the minimum value (namely, 0.0464) and then turns up to 0.054 . Obviously, the minimum value of the soot concentration is obtained when $r / R=0.6$.

As shown in Figure 8, some phenomena can be expressed as follows:

(1) The soot concentration will be increased sharply in axial direction inside filter when $r / R=0$

(2) The soot concentration will be decreased gradually in axial direction when $r / R=0.7$ (i.e., $Y=55 \mathrm{~mm}$ )

Corresponding interpretations for above phenomena are expressed as follows:

(1) There is the large axial velocity and small radial velocity near the center line of the expansion pipe, which causes the exhaust particulates being gathered near the filter midline. Moreover, due to coupling effect from the gradual decrease of the axial velocity and the gradual increase of the radial velocity in the expansion pipe region, there is a vortex region in the expansion pipe. The vortex region will lead to decreasing the polymerization degree of the particle and the soot concentration

(2) When $r / R=0.7$ (i.e., $Y=55 \mathrm{~mm}$ ), there is a biggest vortex intensity in the expansion pipe and the biggest vortex intensity makes the soot concentration of the position be smallest. When the value of the $r / R$ continues to increase, the degree of the particle polymerization begins to increase again due to the gradual decrease of the vortex intensity; therefore, the soot concentration will turn back to increase

The above analysis reveals that the distribution characteristics of the soot concentration in the diesel particulate 
filter are determined by the velocity distribution of the exhaust gas in the expansion pipe region. Therefore, the biggest factor affecting the concentration distribution in the diesel particulate filter is the vortex phenomenon in the expansion pipe region.

\section{Conclusions}

Energy crisis [37-40] promotes the more stringent emission regulations enacted by governments around the world, which means that it is very urgent to develop new combustion [4143] and emission reduction technology [44-50] for minimizing engine emissions [51-54]. In the paper, a mathematical model of gas-particle flow characteristics is established and employed to investigate the characteristics of gas-particle flow. The conclusions are expressed as follows:

(a) There is a larger static pressure phenomenon in the inlet-end when $r / R$ is equal to 0.00 , and there is a big static pressure gradient along the radial distribution which easily leads to stress concentration of the front-end of the filter and causes fatigue damage

(b) The important factor in affecting the soot concentration distribution in the diesel particulate filter is the vortex phenomenon in the expansion pipe region. The weaker the vortex strength is, the better the uniformity of velocity and soot concentration distribution are

(c) In order to improve the velocity uniformity of distribution and soot concentration distribution, the structure improvement of the diesel particulate filter should be applied to reduce vortex strength in the future work

(d) The simulation results of the flow velocity of the diesel particulate filter in each section fundamentally agree with the experimental results, and the relative error is in the allowable range; therefore, the established mathematical model is reliable

The results of the study have recommended a mathematical model that investigates accurately the distribution characteristics of gas-particle two-phase flow in the diesel particulate filter in the capture process. This improvement is helpful to reduce the soot emission of diesel engine, so as to reduce the energy and environmental problems caused by traditional fuel combustion. In future studies, the effects of structural parameters on the capture process in DPF will be investigated.

\section{Nomenclature}

$C_{1 \varepsilon}: \quad$ The model constants

$C_{2 \varepsilon}:$ The model constants

$D: \quad$ The diameter of air inlet pipe, $\mathrm{m}$

$F_{\text {in }}$ : The inlet velocity of exhaust gas, $\mathrm{m} / \mathrm{s}$

$F_{\text {lift,in }}$ : The interaction force, $\mathrm{N}$

$F_{V m, \text { in }}$ : The external body force, $\mathrm{N}$
$G_{k, m}: \quad$ The production term of turbulent kinetic energy

$k: \quad$ The turbulent kinetic energy, $\mathrm{m}^{2} / \mathrm{s}^{2}$

Re: $\quad$ The Reynolds number

$R_{\text {in }}: \quad$ The velocity in direction $y$ of the gas-phase, $\mathrm{m} / \mathrm{s}$

$U: \quad$ The fluid velocity, $\mathrm{m} / \mathrm{s}$

$v: \quad$ The kinematic viscosity, $\mathrm{m}^{2} / \mathrm{s}$

ui: The velocity of exhaust gas in direction $x, \mathrm{~m} / \mathrm{s}$

$u_{\text {in }}: \quad$ Inlet velocity in direction $x$ of the gas-phase, $\mathrm{m} / \mathrm{s}$

$\mu_{t, m}: \quad$ The turbulent viscosity, Pa.s

$v_{i}: \quad$ The velocity of exhaust gas in direction $y, \mathrm{~m} / \mathrm{s}$

$w_{i}$ : The velocity of exhaust gas in direction $z, \mathrm{~m} / \mathrm{s}$.

\section{Greek Symbol}

$\alpha_{i}: \quad$ The volume fraction, $\%$

$\rho: \quad$ The material density of gas-phase, $\mathrm{kg} / \mathrm{m}^{3}$

$\rho_{b}:$ The particle apparent density, $\mathrm{kg} / \mathrm{m}^{3}$

$\rho_{s}:$ The material density, $\mathrm{kg} / \mathrm{m}^{3}$

$\rho_{m}:$ The mixed density, $\mathrm{kg} / \mathrm{m}^{3}$

$\varepsilon: \quad$ The turbulent dissipation rate, $\%$

$\delta: \quad$ The porosity of porous medium

$\sigma_{\varepsilon}: \quad$ The model constants

$\sigma_{k}:$ The Prandtl number

$\tau: \quad$ The pressure-strain tensor, $\mathrm{N}$

$\kappa: \quad$ The seepage rate, $\%$

$\sum m$ : The quality source propagation of gas-phase.

\section{Data Availability}

(1) All data used to support the findings of this study are included within the article. (2) The data used to support the findings of this study are available from the corresponding author upon request.

\section{Conflicts of Interest}

The authors declare that they have no conflict of interests regarding the publication of this paper.

\section{Acknowledgments}

This work is supported by the Natural Science Foundation of Guangxi Province under the research grants of 2018GXNSFAA281267 and 2018GXNSFAA294072. This work is also supported by the Guangxi Young and middleaged college Teachers Basic Research Ability Promotion Project under the research grant of 2020KY39008 and the Key Scientific Research Projects of Guangxi Vocational \& Technical Institute of Industry under the research grant of 2019015 KY025.

\section{References}

[1] D. Zhao and L. Li, "Effect of choked outlet on transient energy growth analysis of a thermoacoustic system," Applied Energy, vol. 160, pp. 502-510, 2015.

[2] D. Zhao, E. Gutmark, and P. D. Goey, "A review of cavitybased trapped vortex, ultra-compact, high-g, inter-turbine combustors," Progress in Energy \& Combustion Science, vol. 66, pp. 42-82, 2018. 
[3] D. Zhao, C. Ji, X. Li, and S. Li, "Mitigation of premixed flamesustained thermoacoustic oscillations using an electrical heater," International Journal of Heat \& Mass Transfer, vol. 86, pp. 309-318, 2015.

[4] J. E, M. H. Pham, Y. Deng et al., "Effects of injection timing and injection pressure on performance and exhaust emissions of a common rail diesel engine fueled by various concentrations of fish-oil biodiesel blends," Energy, vol. 149, pp. 979989, 2018.

[5] J. E, X. Zhao, G. Liu et al., "Effects analysis on optimal microwave energy consumption in the heating process of composite regeneration for the diesel particulate filter," Applied Energy, vol. 254, Article ID 113736, 2019.

[6] J. Q. E, G. Liu, Z. Zhang et al., "Effect analysis on cold starting performance enhancement of a diesel engine fueled with biodiesel fuel based on an improved thermodynamic model," Applied Energy, vol. 243, pp. 321-335, 2019.

[7] J. Q. E, W. Zuo, J. Gao, Q. Peng, Z. Zhang, and P. Hieu, "Effect analysis on pressure drop of the continuous regenerationdiesel particulate filter based on $\mathrm{NO}_{2}$ assisted regeneration," Applied Thermal Engineering, vol. 100, pp. 356-366, 2016.

[8] J. Q. E, Z. Zhang, J. Chen et al., "Performance and emission evaluation of a marine diesel engine fueled by water biodiesel-diesel emulsion blends with a fuel additive of a cerium oxide nanoparticle," Energy Conversion and Management, vol. 169, pp. 194-205, 2018.

[9] G. Wu, D. Wu, Y. L. Li, and M. Lei, "Effect of acetone-n-butanol-ethanol $(\mathrm{ABE})$ as an oxygenate on combustion, performance, and emission characteristics of a spark ignition engine," Journal of Chemistry, vol. 2020, Article ID 7468651, 11 pages, 2020.

[10] Z. Z. Zhang, J. Q. E, J. W. Chen et al., "Effects of boiling heat transfer on the performance enhancement of a medium speed diesel engine fueled with diesel and rapeseed methyl ester," Applied Thermal Engineering, vol. 169, article 114984, 2020.

[11] J. Q. E, M. Liu, Y. W. Deng, H. Zhu, and J. K. Gong, "Influence analysis of monolith structure on regeneration temperature in the process of microwave regeneration in the diesel particulate filter," Canadian Journal of Chemical Engineering, vol. 94, no. 1, pp. 168-174, 2016.

[12] J. Q. E, L. F. Xie, Q. S. Zuo, and G. J. Zhang, "Effect analysis on regeneration speed of continuous regeneration-diesel particulate filter based on $\mathrm{NO}_{2}$-assisted regeneration," Atmospheric Pollution Research, vol. 7, no. 1, pp. 9-17, 2016.

[13] G. Wu, Z. L. Li, S. Abubakar, Y. L. Li, and Y. Q. Li, "Numerical study on effects of key factors on performance of CeO2-based catalyzed diesel particulate filter," Journal of Thermal Science, vol. 29, pp. 1398-1409, 2019.

[14] Q. S. Zuo, Y. Xie, J. Q. E et al., "Effect of different exhaust parameters on NO conversion efficiency enhancement of a dual-carrier catalytic converter in the gasoline engine," Energy, vol. 191, article 116521, 2020.

[15] D. A. Jaffe, G. Hof, S. Malashanka et al., "Diesel particulate matter emission factors and air quality implications from inservice rail in Washington State, USA," Atmospheric Pollution Research, vol. 5, no. 2, pp. 344-351, 2014.

[16] D. C. Quiros, S. Yoon, H. A. Dwyer, J. F. Collins, Y. F. Zhu, and T. Huai, "Measuring particulate matter emissions during parked active diesel particulate filter regeneration of heavyduty diesel trucks," Journal of Aerosol Science, vol. 73, pp. 48-62, 2014.
[17] M. P. Orihuela, R. Chacartegui, and J. Martínez-Fernández, "New biomorphic filters to face upcoming particulate emissions policies: a review of the FIL-BIO-DIESEL project," Energy, vol. 201, article 117577, 2020.

[18] Q. S. Zuo, Y. Xie, Q. W. Guan et al., "Effect of critical dualcarrier structure parameters on performance enhancement of a dual-carrier catalytic converter and the gasoline engine system," Energy Conversion and Management, vol. 204, article 112325, 2020.

[19] M. P. Orihuela, R. Chacartegui, A. Gómez-Martín, J. RamírezRico, and J. A. Becerra Villanueva, "Performance trends in wall-flow diesel particulate filters: comparative analysis of their filtration efficiency and pressure drop," Journal of Cleaner Production, vol. 260, article 120863, 2020.

[20] M. P. Orihuela, A. Gómez-Martín, P. Miceli, J. A. Becerra, R. Chacartegui, and D. Fino, "Experimental measurement of the filtration efficiency and pressure drop of wall-flow diesel particulate filters (DPF) made of biomorphic silicon carbide using laboratory generated particles," Applied Thermal Engineering, vol. 131, pp. 41-53, 2017.

[21] B. Azambre, S. Collura, P. Darcy et al., "Effects of a $\mathrm{Pt} / \mathrm{Ce}_{0.68} \mathrm{Zr}_{0.32} \mathrm{O}_{2}$ catalyst and $\mathrm{NO}_{2}$ on the kinetics of diesel soot oxidation from thermogravimetric analyses," Fuel Processing Technology, vol. 92, no. 3, pp. 363-371, 2011.

[22] Z. Z. Zhang, J. Q. E, J. W. Chen et al., "Effects of low-level water addition on spray, combustion and emission characteristics of a medium speed diesel engine fueled with biodiesel fuel," Fuel, vol. 239, pp. 245-262, 2019.

[23] Y. Q. Liu, J. K. Gong, J. Fu, H. Cai, and G. Long, "Nanoparticle motion trajectories and deposition in an inlet channel of wallflow diesel particulate filter," Journal of Aerosol Science, vol. 40, no. 4, pp. 307-323, 2009.

[24] Z. Z. Zhang, J. Q. E, Y. W. Deng et al., "Effects of fatty acid methyl esters proportion on combustion and emission characteristics of a biodiesel fueled marine diesel engine," Energy Conversion and Management, vol. 159, pp. 244-253, 2018.

[25] K. Chen, K. S. Martirosyan, and D. Luss, "Transient temperature rise during regeneration of diesel particulate filters," Chemical Engineering Journal, vol. 176-177, pp. 144-150, 2011.

[26] Q. S. Zuo, J. Q. E, J. K. Gong, D. M. Zhang, T. Chen, and G. H. Jia, "Performance evaluation on field synergy and composite regeneration by coupling cerium-based additive and microwave for a diesel particulate filter," Journal of Central South University, vol. 21, no. 12, pp. 4599-4606, 2014.

[27] B. Zhang, H. Y. Zuo, Z. H. Huang, J. Q. Tan, and Q. S. Zuo, "Endpoint forecast of different diesel-biodiesel soot filtration process in diesel particulate filters considering ash deposition," Fuel, vol. 272, article 117678, 2020.

[28] F. Piscaglia and G. Ferrari, "A novel 1D approach for the simulation of unsteady reacting flows in diesel exhaust aftertreatment systems," Energy, vol. 34, no. 12, pp. 2051-2062, 2009.

[29] K. C. Premchand, J. H. Johnson, and S. Yang, "Development of a 1-D CPF model to simulate active regeneration of a diesel particulate filter," in World Congress \& Exhibition, April 4023, 2009, pp. 1-5, Society of Automotive Engineers (SAE), Detroit, MI, USA, 2009.

[30] J. R. Serrano, F. J. Arnau, P. Piqueras, and Ó. García-Afonso, "Packed bed of spherical particles approach for pressure drop prediction in wall-flow DPFs (diesel particulate filters) under soot loading conditions," Energy, vol. 58, pp. 644-654, 2013. 
[31] A. J. Torregrosa, J. R. Serrano, F. J. Arnau, and P. Piqueras, “A fluid dynamic model for unsteady compressible flow in wallflow diesel particulate filters," Energy, vol. 36, no. 1, pp. 671684, 2011.

[32] J. Q. E, Q. Zuo, H. Liu, Y. Li, and J. Gong, "Endpoint forecasting on composite regeneration by coupling cerium-based additive and microwave for diesel particulate filter," Journal of Central South University, vol. 23, no. 8, pp. 2118-2128, 2016.

[33] B. Zhang, J. Q. E, J. Gong, W. Yuan, W. Zuo, and F. J. LiY, "Multidisciplinary design optimization of the diesel particulate filter in the composite regeneration process," Applied Energy, vol. 181, pp. 14-28, 2016.

[34] M. Masoudi, A. G. Konstandopoulos, M. S. Nikitidis et al., "Validation of a model and development of a simulator for predicting the pressure drop of diesel particulate filters," in Society of Automotive Engineers(SAE) 2001 Transactions Journal of Fuels and Lubricants, pp. 184-202, USA, 2001.

[35] B. E. Launder and D. B. Spalding, Lectures in Mathematical Models of Turbulence, Academic Press, London, 1972.

[36] J. Q. E, X. Zhao, L. Xie et al., "Performance enhancement of microwave assisted regeneration in a wall-flow diesel particulate filter based on field synergy theory," Energy, vol. 169, pp. 719-729, 2019.

[37] K. Wei, Y. Yang, H. Zuo, and D. Zhong, "A review on ice detection technology and ice elimination technology for wind turbine," Wind Energy, vol. 23, no. 3, pp. 433-457, 2020.

[38] H. Zuo, G. Liu, J. Q. E et al., "Catastrophic analysis on the stability of a large dish solar thermal power generation system with wind-induced vibration," Solar Energy, vol. 183, pp. 4049, 2019.

[39] H. Zuo, J. Tan, K. Wei, Z. Huang, D. Zhong, and F. Xie, "Effects of different poses and wind speeds on wind-induced vibration characteristics of a dish solar concentrator system," Renewable Energy, vol. 168, pp. 1308-1326, 2021.

[40] F. Zhang, G. Liao, J. Q. E, J. W. Chen, and E. W. Leng, "Comparative study on the thermodynamic and economic performance of novel absorption power cycles driven by the waste heat from a supercritical $\mathrm{CO}_{2}$ cycle," Energy Conversion and Management, vol. 228, article 113671, 2021.

[41] D. Zhao, E. Gutmark, and P. D. Goey, "A review of cavitybased trapped vortex, ultracompact, high-g, inter-turbine combustors," Progress in Energy and Combustion Science, vol. 66, pp. 42-82, 2018.

[42] H. Chu, L. Xiang, X. Nie, Y. Ya, M. Gu, and E. Jiaqiang, "Laminar burning velocity and pollutant emissions of the gasoline components and its surrogate fuels: a review," Fuel, vol. 269, article 117451, 2020.

[43] Q. G. Peng, W. M. Yang, J. Q. E et al., "Investigation on $\mathrm{H}_{2} /$ air combustion with $\mathrm{C}_{3} \mathrm{H}_{8}$ addition in the combustor with part/full porous medium," Energy Conversion and Management, vol. 228, article 113652, 2021.

[44] Q. Zuo, Y. Tang, W. Chen, J. Zhang, L. Shi, and Y. Xie, "Effects of exhaust parameters on gasoline soot regeneration performance of a catalytic gasoline particulate filter in equilibrium state," Fuel, vol. 265, article 117001, 2020.

[45] Y. Deng, C. Feng, J. E et al., "Performance enhancement of the gasoline engine hydrocarbon catchers for reducing hydrocarbon emission during the cold-start period," Energy, vol. 183, pp. 869-879, 2019.

[46] E. Jiaqiang, M. Pham, D. Zhao et al., "Effect of different technologies on combustion and emissions of the diesel engine fueled with biodiesel: a review," Renewable and Sustainable Energy Reviews, vol. 80, pp. 620-647, 2017.

[47] H. Chu, Y. Ya, X. Nie, F. Qiao, and E. Jiaqiang, "Effects of adding hexamethylene, n-hexane, ethanol, and 2, 5-dimethylfuran to fuel on soot formation in laminar coflow n-heptane/isooctane diffusion flame," Combustion and Flame, vol. 225, pp. 120-135, 2021.

[48] X. H. Zhao, J. Q. E, G. L. Liao, F. Zhang, J. W. Chen, and Y. W. Deng, "Numerical simulation study on soot continuous regeneration combustion model of diesel particulate filter under exhaust gas heavy load," Fuel, vol. 287, article 119795, 2020.

[49] D. D. Han, E. JQ, Y. W. Deng et al., “A review of studies using hydrocarbon reduction measures for reducing hydrocarbon emissions from cold start of gasoline engine," Renewable \& Sustainable Energy Reviews, vol. 135, article 110079, 2021.

[50] G. Wu, X. Wang, S. Abubakar, Y. Li, and Z. Liu, "A realistic skeletal mechanism for the oxidation of biodiesel surrogate composed of long carbon chain and polyunsaturated compounds," Fuel, vol. 289, article 119934, 2021.

[51] Z. Zhang, J. Ye, D. Tan et al., "The effects of $\mathrm{Fe}_{2} \mathrm{O}_{3}$ based DOC and SCR catalyst on the combustion and emission characteristics of a diesel engine fueled with biodiesel," Fuel, vol. 291, article 120039, 2021.

[52] J. E, M. Zhao, Q. Zuo et al., "Effects analysis on diesel soot continuous regeneration performance of a rotary microwaveassisted regeneration diesel particulate filter," Fuel, vol. 260, Article ID 116353, 2020.

[53] Y. Xie, Q. Zuo, M. Wang et al., "Effects analysis on soot combustion performance enhancement of an improved catalytic gasoline particulate filter regeneration system with electric heating," Fuel, vol. 290, Article ID 119975, 2021.

[54] Y. Xie, Q. Zuo, G. Zhu et al., "Investigations on the soot combustion performance enhancement of an improved catalytic gasoline particulate filter regeneration system under different electric heating powers," Fuel, vol. 283, article 119301, 2021. 